\title{
Suppressing diborane production during the hydrogen release of metal borohydrides: The example of alloyed $\mathrm{Al}\left(\mathrm{BH}_{4}\right)_{3}$
}

\author{
D. Harrison, T. Thonhauser* \\ Department of Physics, Wake Forest University, Winston-Salem, NC 27109, USA.
}

\begin{abstract}
Aluminum borohydride $\left(\mathrm{Al}\left(\mathrm{BH}_{4}\right)_{3}\right)$ is an example of a promising hydrogen storage material with exceptional hydrogen densities by weight and volume and a low hydrogen desorption temperature. But, unfortunately, its production of diborane $\left(\mathrm{B}_{2} \mathrm{H}_{6}\right)$ gases upon heating to release the hydrogen restricts its practical use. To elucidate this issue, we investigate the properties of a number of metal borohydrides with the same problem and find that the electronegativity of the metal cation is not the best descriptor of diborane production. We show that, instead, the closely related formation enthalpy is a better descriptor and we find that diborane production is an exponential function thereof. We conclude that diborane production is sufficiently suppressed for formation enthalpies of $-80 \mathrm{~kJ} / \mathrm{mol} \mathrm{BH}_{4}$ or lower, providing specific design guidelines to tune existing metal borohydrides or synthesize new ones. We then use first-principles methods to study the effects of $\mathrm{Sc}$ alloying in $\mathrm{Al}\left(\mathrm{BH}_{4}\right)_{3}$. Our results for the thermodynamic properties of the $\mathrm{Al}_{1-x} \mathrm{Sc}_{x}\left(\mathrm{BH}_{4}\right)_{3}$ alloy clearly show the stabilizing effect of Sc alloying and thus the suppression of diborane production. We conclude that stabilizing $\mathrm{Al}\left(\mathrm{BH}_{4}\right)_{3}$ and similar borohydrides via alloying or other means is a promising route to suppress diborane production and thus develop viable hydrogen storage materials.
\end{abstract}

Keywords: Hydrogen storage, Metal borohydrides, Aluminum borohydride, Thermodynamics, First-principles calculations

\footnotetext{
* Corresponding author

Email address: thonhauser@wfu.edu (T. Thonhauser)
} 


\section{Introduction}

Hydrogen has been identified as a promising alternative to fossil fuels due to its potential to be a clean, renewable energy carrier [1, 2, 3]. However, in its natural state, hydrogen has an unsuitably low volumetric density for automotive applications, leading to much research on more effective hydrogen storage methods 4, 5, with clear goals outlined by the Department on Energy (DOE) [6, 7. Borohydrides are a class of complex hydrides which are of interest due to their high gravimetric and volumetric densities, although they typically suffer from hydrogen desorption temperatures over $85{ }^{\circ} \mathrm{C}$, i.e. the maximum delivery temperature set by the DOE for fuel cell operation in vehicles [6, 8, 9, 10, 11, 12, 13, 14, 15.

Of particular interest is aluminum borohydride $\left(\mathrm{Al}\left(\mathrm{BH}_{4}\right)_{3}\right)$, due in part to its high storage density of 16.9 mass\%, but primarily because of its significantly lower initial hydrogen release temperature of $334 \mathrm{~K}\left(61^{\circ} \mathrm{C}\right)$ compared to other borohydrides [16, 17]. Despite these advantages, $\mathrm{Al}\left(\mathrm{BH}_{4}\right)_{3}$ has not received as much attention as other borohydrides - partly due to its cost, but mainly because of diborane production during its hydrogen release [18, 19. In addition to reducing $\mathrm{H}_{2}$ output, diborane is also poisonous to the fuel cell, reducing fuel cell performance by $39 \%$ while present, although full recovery is retainable once diborane is removed from the fuel stream 20. This production of diborane is due to the instability of the material itself: the difference in energy between the $\mathrm{Al}\left(\mathrm{BH}_{4}\right)_{3}$ molecule and solid phases is rather small, causing solid $\mathrm{Al}\left(\mathrm{BH}_{4}\right)_{3}$ to be composed of discrete molecular $\mathrm{Al}\left(\mathrm{BH}_{4}\right)_{3}$ units held together by weak van der Waals interactions. These weak interactions among the $\mathrm{Al}\left(\mathrm{BH}_{4}\right)_{3}$ molecules are also responsible for its low melting point of $209 \mathrm{~K}$ [21, 19.

Many methods have been used in order to alter the properties of various borohydrides, including destabilizing via reactions with other hydrides [22, 23. [24, 16], alloying [25, 26, 27], cation substitution [28, anion substitution [29, and adding catalysts 30 . In general, the goal of most of these methods is to lower the hydrogen desorption temperature by altering either the kinetics or thermodynamics of the reaction. Here, we proposed to use the same kind of methods, but instead take a material with an already low desorption temperature and try to suppress its undesirable diborane production.

The production of diborane in a borohydride is correlated to the Pauling electronegativity $\chi_{P}$ of its metal cation, as established by Nakamori et al. 31, 17. In Fig. 1. we show $\chi_{P}$ vs. the amount of diborane production (relative to hydrogen produced) as measured by integrating the mass-spectroscopy data [17; for a given borohydride, we took the ratio of the integrated $\mathrm{B}_{2} \mathrm{H}_{6}$ data to the integrated $\mathrm{H}_{2}$ data, normalized so that $\mathrm{Al}\left(\mathrm{BH}_{4}\right)_{3}$ has a value of 1 . As can be seen, the amount of diborane produced does not follow any clear trend as a function of $\chi_{P}$. The only thing that can be said is that somewhere between $1.36<\chi_{P}<1.55$ diborane production starts. These are rather course boundaries, providing little guidance for tuning borohydrides, and they do not reveal information about the amount of diborane produced. A better predictor is thus desirable. 


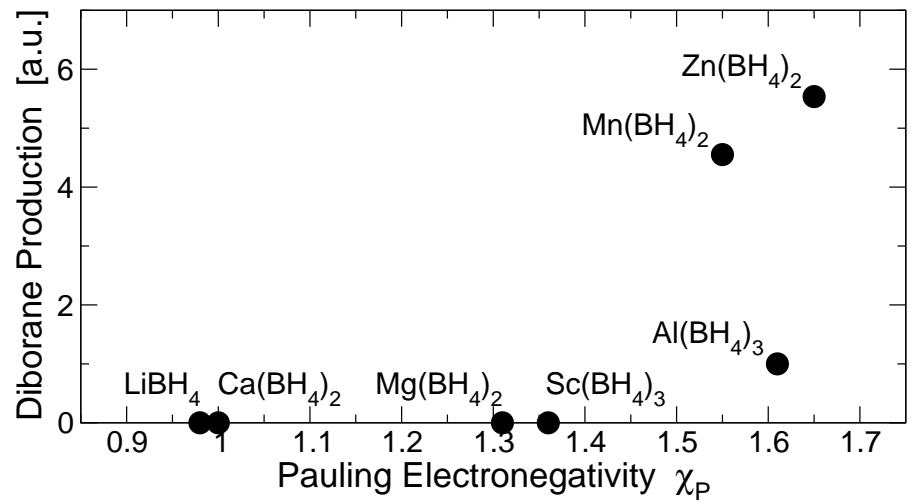

Figure 1: Plot of diborane production vs. $\chi_{P}$ for various metal borohydrides. Diborane production data was obtained by integrating mass-spectroscopy data from Nakamori et al. 17. Values for $\chi_{P}$ for the metal cation are taken from Ref. 32. Amount of diborane produced does not follow a clear trend as a function of $\chi_{P}$.

It is also known that, as the stability of a borohydride is largely due to the charge transfer between the metal cation and the anionic $\left[\mathrm{BH}_{4}\right]^{-}$unit, $\chi_{P}$ is also strongly correlated with the enthalpy of formation 21. We hypothesized that by lowering the enthalpy of formation of $\mathrm{Al}\left(\mathrm{BH}_{4}\right)_{3}$ (i.e. stabilizing it), the production of diborane upon heating is suppressed. Because the enthalpy of formation of borohydrides is so strongly correlated with the cation electronegativity, alloying with a more (less) electronegative cation is an effective method to increase (decrease) the formation enthalpy. As seen in our previous work and other works studying the effect of alloying on borohydrides, we expect that the enthalpy of formation of the alloyed material is approximately the weighted average of the two materials in their pure state (i.e. the enthalpy of mixing is small) [33, 34].

In choosing which metal to alloy $\mathrm{Al}\left(\mathrm{BH}_{4}\right)_{3}$ with, we try to satisfy three criteria: (i) the metal should have a lower electronegativity than aluminum, (ii) it should have a valence of 3 , and (iii) it should be relatively lightweight in order to preserve the high hydrogen mass density for the alloyed material. For these reasons, we chose scandium, which in addition to fulfilling these criteria is known to form a stable borohydride $\mathrm{Sc}\left(\mathrm{BH}_{4}\right)_{3}$ that does not produce diborane gas upon decomposition [17. For reference, a number of studies on other borohydride alloys involving $\mathrm{Sc}$ or $\mathrm{Al}$ have already been reported [35, 36, 37, 38, 39, 40.

In order to demonstrate the effect of scandium on $\mathrm{Al}\left(\mathrm{BH}_{4}\right)_{3}$, we first verify that Sc alloying stabilizes $\mathrm{Al}\left(\mathrm{BH}_{4}\right)_{3}$ by calculating how the temperaturedependent enthalpy of formation changes with Sc concentration. However, in order to estimate the amount of $\mathrm{Sc}$ needed to alloy $\mathrm{Al}\left(\mathrm{BH}_{4}\right)_{3}, \chi_{P}$ cannot be used as a predictor for the reasons explained above. In the search for a better predictor, we determine the relationship between the stability of the borohydride (i.e. formation enthalpy) and the amount of diborane produced. To this end, we consult the mass-spectroscopy data of Nakamori et al., wherein we analyze 
their data in order to determine the relative diborane production of $\mathrm{Al}\left(\mathrm{BH}_{4}\right)_{3}$, $\mathrm{Zn}\left(\mathrm{BH}_{4}\right)_{2}$, and $\mathrm{Mn}\left(\mathrm{BH}_{4}\right)_{2}$, the only borohydrides to produce diborane in any significant amount [17; we then calculate the thermodynamics of these borohydrides so that we can find a more quantitative relationship between formation enthalpy and diborane production. Using this relationship as well as data from previous borohydride alloy studies, we estimate the ideal diborane production.

\section{Computational Details}

\subsection{General}

In order to obtain high-accuracy results on the thermodynamics of $\mathrm{Al}\left(\mathrm{BH}_{4}\right)_{3}$, we performed $a b$ initio simulations using density-functional theory (DFT) as implemented in VASP [41, 42. We used the standard projector augmented wave (PAW) pseudopotentials included in VASP with a $450 \mathrm{eV}$ kinetic energy cutoff. The energy convergence criterion was $10^{-7} \mathrm{eV}$. The structure used for $\mathrm{Al}\left(\mathrm{BH}_{4}\right)_{3}$ was the solid-phase $\beta-\mathrm{Al}\left(\mathrm{BH}_{4}\right)_{3}$ taken from the theoretical work of Miwa et al. [21, 43, the structure for $\mathrm{Mn}\left(\mathrm{BH}_{4}\right)_{2}$ was taken from the theoretical work of Choudhury et al. [4], the structures for $\mathrm{Sc}\left(\mathrm{BH}_{4}\right)_{3}$ and $\mathrm{Zn}\left(\mathrm{BH}_{4}\right)_{2}$ were taken from Nakamori et al. [31, and the structure for B was the 106 atom $\beta$ rhombohedral structure suggested by van Setten et al. 45 . A fixed $10 \times 10 \times 10 \AA$ unit cell was used for gas-phase $\mathrm{H}_{2}$. The $k$-point meshes for $\mathrm{Al}\left(\mathrm{BH}_{4}\right)_{3}$ (including Sc alloying), $\mathrm{Mn}\left(\mathrm{BH}_{4}\right)_{2}, \mathrm{Zn}\left(\mathrm{BH}_{4}\right)_{2}, \mathrm{~B}, \mathrm{Al}, \mathrm{Sc}, \mathrm{Mn}$, and $\mathrm{Zn}$ were $2 \times 2 \times 1,2 \times 2 \times 2$, $2 \times 3 \times 2,2 \times 2 \times 2,15 \times 15 \times 15,21 \times 21 \times 12,5 \times 5 \times 5$, and $17 \times 17 \times 7$, respectively. All k-point meshes were converged within $1 \mathrm{meV}$ per atom with respect to much larger meshes. All structures were relaxed with respect to unit-cell parameters and atom positions until all forces were less than $0.2 \mathrm{meV} / \AA$.

Sc-alloying was done by replacing a random $\mathrm{Al}$ atom with a $\mathrm{Sc}$ atom and then relaxing the structure; as the unit cell of $\mathrm{Al}\left(\mathrm{BH}_{4}\right)_{3}$ contains $4 \mathrm{Al}$ atoms, 25,50 , and $75 \%$ alloying was done by replacing 1, 2, and $3 \mathrm{Al}$ atoms with Sc. Energy differences due to which atom was replaced were found to be small (less than $3 \mathrm{~kJ} / \mathrm{mol}$ ) compared to the energy difference due to alloying. Frequency calculations were done with the symmetry-reduced finite-displacement method with the recommended displacement of $0.015 \AA$. Supercells used in the frequency calculations for $\mathrm{Al}\left(\mathrm{BH}_{4}\right)_{3}, \mathrm{Mn}\left(\mathrm{BH}_{4}\right)_{2}, \mathrm{Zn}\left(\mathrm{BH}_{4}\right)_{2}, \mathrm{~B}, \mathrm{Al}, \mathrm{Sc}, \mathrm{Mn}$, and $\mathrm{Zn}$ were $2 \times 2 \times 1,1 \times 1 \times 1,2 \times 2 \times 2,1 \times 1 \times 1,3 \times 3 \times 3,5 \times 5 \times 3,1 \times 1 \times 1$, and $5 \times 5 \times 3$, respectively.

Previous studies on $\mathrm{Al}\left(\mathrm{BH}_{4}\right)_{3}$ found that van der Waals interactions are important to accurately model the material due to weak interactions among the discrete molecular $\mathrm{Al}\left(\mathrm{BH}_{4}\right)_{3}$ units [21, 19]. For this reason, in order to obtain accurate thermodynamic results, we employed the exchange-correlation functional vdW-DF [46, 47, 48, 49, which includes a truly nonlocal correlation term to capture van der Waals binding. In order to ascertain the effect of van der Waals interactions, comparisons to previous studies are made below. 


\subsection{Enthalpies, Entropies, and Mixing}

The temperature dependent vibrational contribution to the enthalpy and entropy is calculated as

$$
\begin{aligned}
H_{\mathrm{vib}} & =\int_{0}^{\infty} d \omega\left(\frac{1}{2}+\frac{1}{\exp [\hbar \omega / k T]-1}\right) g(\omega) \hbar \omega \\
S_{\mathrm{vib}} & =\int_{0}^{\infty} d \omega\left(\frac{\hbar \omega}{2 T} \operatorname{coth} \frac{\hbar \omega}{2 k T}-k \ln \left[2 \sinh \frac{\hbar \omega}{2 k T}\right]\right) g(\omega),
\end{aligned}
$$

where $T$ is the temperature, $k$ is Boltzmann's constant, $\omega$ is the vibrational frequency, and $g(\omega)$ is the phonon density of states. The phonon density of states was calculated using the program phonopy [50]. The total enthalpy then is the sum of the DFT ground-state energy and this vibrational contribution. Note that the zero-point energy (ZPE) is already included in Eq. (1). The formation enthalpy is calculated as the difference in the enthalpies of the material and its constituent elements (thus, elements in their natural state have formation enthalpies of 0 ). We then can calculate the enthalpies and entropies of reaction, using the differences in formation enthalpies and absolute entropies of all materials. One notable exception is $\mathrm{H}_{2}$ : due to it being a gas we calculated its ground state and zero-point energy, but took the temperature-dependent contribution from experiment, following the approach of van Setten et al. [51, 52. Particularly, we used $H_{\mathrm{H}_{2} \text { gas }}(T)=E_{\mathrm{H}_{2}}+E_{\mathrm{H}_{2}}^{\mathrm{ZPE}}+H_{\mathrm{H}_{2} \text { gas }}^{\text {exp }}(T)$, where the electronic energy $E_{\mathrm{H}_{2}}$ and zero-point energy $E_{\mathrm{H}_{2}}^{\mathrm{ZPE}}$ were calculated using DFT and the last term was taken from known experimental values [52]. For reactions involving Sc alloying, the entropy of mixing was calculated according to

$$
S_{\mathrm{mix}}=-k_{B}[c \ln c+(1-c) \ln (1-c)],
$$

where $c$ is the concentration of Sc, but it was found to be negligible.

\section{Results and Discussion}

\subsection{Structure of $\mathrm{Al}\left(\mathrm{BH}_{4}\right)_{3}$ and Importance of van der Waals Interactions}

As mentioned, van der Waals interactions were found to be an important factor in accurately modeling $\mathrm{Al}\left(\mathrm{BH}_{4}\right)_{3}$ due to the weak interactions among the discrete molecular units [21, 19. A previous study on $\mathrm{Al}\left(\mathrm{BH}_{4}\right)_{3}$ by Miwa et al. found lattice constants for $\beta-\mathrm{Al}\left(\mathrm{BH}_{4}\right)_{3}$ of $a=18.649 \AA, b=6.488 \AA$, and $c=6.389 \AA$, whereas we find values of $a=17.917 \AA, b=6.026 \AA$, and $c=6.022 \AA$, in much better agreement with the experimental values of $a=$ $18.021 \AA, b=6.138 \AA$, and $c=6.199 \AA$ [21, 43]. As described by Miwa et al., this discrepancy is likely due to weak van der Waals interactions among molecular $\mathrm{Al}\left(\mathrm{BH}_{4}\right)_{3}$ units, which standard functionals are unable to describe. Miwa et al. also calculated the energy of a single molecule of $\mathrm{Al}\left(\mathrm{BH}_{4}\right)_{3}$ and found an energy difference with respect to the solid of only $\sim 10 \mathrm{~kJ} / \mathrm{mol}$, while we, using vdW-DF, calculate a much higher energy difference of $64.6 \mathrm{~kJ} / \mathrm{mol}$. 
Table 1: Formation enthalpies $\Delta H_{f}$ in $\mathrm{kJ} / \mathrm{mol}$; the first column is using only the DFT groundstate energy, the second includes the zero-point energy (ZPE) correction, and the third includes the lattice vibration contribution to the energy at $300 \mathrm{~K}$.

\begin{tabular}{lccr}
\hline \hline Material & $\Delta H_{f}^{E_{\text {only }}}$ & $\Delta H_{f}^{\mathrm{ZPE}}$ & \multicolumn{1}{c}{$\Delta H_{f}^{300 \mathrm{~K}}$} \\
\hline $\mathrm{Al}\left(\mathrm{BH}_{4}\right)_{3}$ & -168.12 & -52.67 & -83.88 \\
$\mathrm{Al}_{3 / 4} \mathrm{Sc}_{1 / 4}\left(\mathrm{BH}_{4}\right)_{3}$ & -214.06 & -100.03 & -131.92 \\
$\mathrm{Al}_{1 / 2} \mathrm{Sc}_{1 / 2}\left(\mathrm{BH}_{4}\right)_{3}$ & -259.39 & -146.60 & -179.22 \\
$\mathrm{Al}_{1 / 4} \mathrm{Sc}_{3 / 4}\left(\mathrm{BH}_{3}\right)_{3}$ & -318.64 & -206.14 & -240.04 \\
$\mathrm{Sc}\left(\mathrm{BH}_{4}\right)_{3}$ & -339.85 & -229.49 & -265.12 \\
\hline \hline
\end{tabular}

To verify our results, we also did an energy calculation on both the solid and molecule without vdW-DF and find an energy difference of only $5.2 \mathrm{~kJ} / \mathrm{mol}$ - in good agreement with the value from Miwa et al. Clearly then, the nonlocal van der Waals interactions are responsible for the majority of the stability of $\mathrm{Al}\left(\mathrm{BH}_{4}\right)_{3}$, and including them is crucial to obtain the most accurate treatment of this material.

\subsection{Structure of Alloyed $\mathrm{Al}\left(\mathrm{BH}_{4}\right)_{3}$}

As described in Section 2.1. Sc-alloying was done by replacing a random $\mathrm{Al}$ atom in the $\mathrm{Al}\left(\mathrm{BH}_{4}\right)_{3}$ structure with a $\mathrm{Sc}$ atom and then relaxing the system. It is conceivable that for higher Sc concentrations the true ground-state structure of the alloys prefer structures that cannot be reached that way, but a truly-random structure search for the alloys is beyond the scope of this paper. However, it is interesting that by analyzing our alloy structures, we observe the trend that the substituted Sc pulls nearby $\mathrm{BH}_{4}$ units close to it. Indeed, we would expect in general for the $\mathrm{BH}_{4}$ units to cluster around the less electronegative cation, as more stable borohydrides (and thus possessing a less electronegative metal) are also more dense and have a higher coordination of $\mathrm{BH}_{4}$ units near the metal [15].

\subsection{Formation Enthalpies}

Table 1 shows the formation enthalpies of $\mathrm{Al}\left(\mathrm{BH}_{4}\right)_{3}$ for various values of Sc-alloying. The formation enthalpy linearly decreases with increasing Sc concentration, showing that $\mathrm{Sc}$ alloying predictably stabilizes $\mathrm{Al}\left(\mathrm{BH}_{4}\right)_{3}$ and that the thermodynamic properties of the alloy are nearly the weighted average of the properties of the pure borohydrides, i.e. $\mathrm{Al}\left(\mathrm{BH}_{4}\right)_{3}$ and $\mathrm{Sc}\left(\mathrm{BH}_{4}\right)_{3}$.

When we compare our $E_{\text {only }}$ formation enthalpy from Table 1 of $\mathrm{Al}\left(\mathrm{BH}_{4}\right)_{3}$ calculated with vdW-DF to the results of Miwa et al. I. we find a surprising disparity: our value of $-168.12 \mathrm{~kJ} / \mathrm{mol}$ to their value of $-131 \mathrm{~kJ} / \mathrm{mol}$ [21].

\footnotetext{
${ }^{1}$ Here, we are comparing our formation enthalpy without ZPE, i.e. $E_{\text {only }}$, as this is what was calculated in Ref. 21 .
} 
Table 2: Reaction enthalpies $\Delta H_{r}$ in $\mathrm{kJ} / \mathrm{mol} \mathrm{H} \mathrm{H}_{2}$ and entropies $\Delta S_{r}$ in $\mathrm{J} / \mathrm{K} / \mathrm{mol} \mathrm{H}_{2}$ at 300 $\mathrm{K}$ for several $\mathrm{Al}\left(\mathrm{BH}_{4}\right)_{3}$ desorption reactions. The critical temperature $T_{c}$ predicted from the van't Hoff equation $\ln p=-\Delta H / R T+\Delta S / R$ for 1 bar $\mathrm{H}_{2}$ pressure is given in $\mathrm{K}$.

\begin{tabular}{lrllrrr}
\hline \hline No. & Reactants & $\longrightarrow$ & Products & $\Delta H_{r}^{300 \mathrm{~K}}$ & $\Delta S_{r}^{300 \mathrm{~K}}$ & $T_{c}$ \\
\hline 1 & $\mathrm{Al}\left(\mathrm{BH}_{4}\right)_{3}$ & $\mathrm{Al}+3 \mathrm{~B}+6 \mathrm{H}_{2}$ & 13.98 & 107.26 & 130 \\
2 & $\mathrm{Al}_{3 / 4} \mathrm{Sc}_{1 / 4}\left(\mathrm{BH}_{4}\right)_{3}$ & $\longrightarrow$ & $\frac{3}{4} \mathrm{Al}+\frac{1}{4} \mathrm{Sc}+3 \mathrm{~B}+6 \mathrm{H}_{2}$ & 21.99 & 107.49 & 205 \\
3 & $\mathrm{Al}_{1 / 2} \mathrm{Sc}_{1 / 2}\left(\mathrm{BH}_{4}\right)_{3}$ & $\longrightarrow$ & $\frac{1}{2} \mathrm{Al}+\frac{1}{2} \mathrm{Sc}+3 \mathrm{~B}+6 \mathrm{H}_{2}$ & 29.87 & 108.57 & 275 \\
4 & $\mathrm{Al}_{1 / 4} \mathrm{Sc}_{3 / 4}\left(\mathrm{BH}_{3}\right)_{3}$ & $\longrightarrow$ & $\frac{1}{4} \mathrm{Al}+\frac{3}{4} \mathrm{Sc}+3 \mathrm{~B}+6 \mathrm{H}_{2}$ & 40.01 & 110.36 & 363 \\
5 & $\mathrm{Sc}\left(\mathrm{BH}_{4}\right)_{3}$ & $\mathrm{Sc}+3 \mathrm{~B}+6 \mathrm{H}_{2}$ & 44.19 & 113.87 & 388 \\
\hline \hline
\end{tabular}

Because of this, we also calculated the formation enthalpy of $\mathrm{Al}\left(\mathrm{BH}_{4}\right)_{3}$ without including van der Waals interactions with vdW-DF, and found a value of $-130 \mathrm{~kJ} / \mathrm{mol}$, in excellent agreement with Miwa et al. This significant difference shows again that the inclusion of van der Waals interactions is particularly important to achieving highly accurate results for $\mathrm{Al}\left(\mathrm{BH}_{4}\right)_{3}$, even more-so than for other borohydrides.

\subsection{Reaction Enthalpies at $300 \mathrm{~K}$ and 1 Bar}

Table 2 shows the reaction enthalpies for the decomposition reactions of $\mathrm{Al}\left(\mathrm{BH}_{4}\right)_{3}$ for various level of Sc-alloying at $300 \mathrm{~K}$ and 1 bar. For consistency's sake, we consider here the decomposition into the elements in order to estimate the stabilizing effect of Sc-alloying and to compare to other theoretical works - of course, the true decomposition reaction for $\mathrm{Al}\left(\mathrm{BH}_{4}\right)_{3}$ is known to produce diborane gas as well as other aluminoborane intermediates, as discussed at length by Łodziana 19 .

From looking at the critical temperature for Reaction 1 of $130 \mathrm{~K}$, although the reaction shows $\mathrm{Al}\left(\mathrm{BH}_{4}\right)_{3}$ to be unstable with respect to its elements at room temperature, it is in fact kinetically stabilized, due to the previously mentioned diborane and aluminoborane intermediates of the true hydrogen desorption reaction. Comparing our value from Reaction 1 of $13.98 \mathrm{~kJ} / \mathrm{mol} \mathrm{H}_{2}$ to the value found by Łodziana of $11.7 \mathrm{~kJ} / \mathrm{mol} \mathrm{H} \mathrm{H}_{2}$ (taken from Fig. 1 of Ref. [19]), we again find our value predicting greater stability for $\mathrm{Al}\left(\mathrm{BH}_{4}\right)_{3}$. This confirms that vdW-DF stabilizes $\mathrm{Al}\left(\mathrm{BH}_{4}\right)_{3}$ on the order of $15-25 \%$ more than standard generalized gradient approximation (GGA) functionals.

From Table 2 we see that the critical temperature for the hydrogen release of the alloy is roughly the weighted average of the critical temperature of the pure borohydrides, i.e. based on our results we would expect approximately a $70 \mathrm{~K}$ increase per $25 \%$ Sc alloying. However, as the hydrogen release in borohydrides is well known to have a large kinetic barrier, the true relationship is likely more complex. In fact, a study by Paskevicius et al. found that borohydride alloys exhibit both lower melting temperatures and lower hydrogen release temperatures than either of the pure borohydrides constituting the alloy [53. In light of this, it is difficult - and beyond the scope of this paper - to accurately estimate the hydrogen release temperature of the alloy, other than to say we 


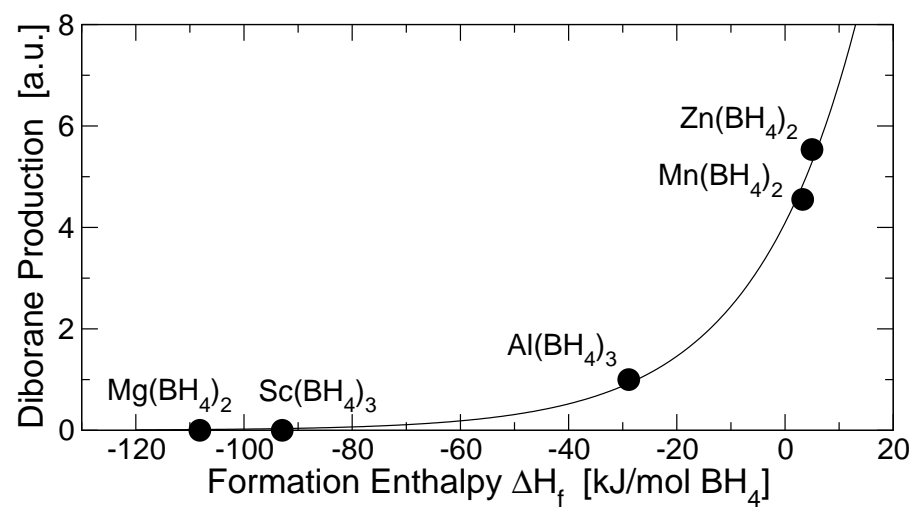

Figure 2: Plot of diborane production versus calculated formation enthalpy $\left[\mathrm{kJ} / \mathrm{mol} \mathrm{BH}_{4}\right]$. Diborane production data was obtained by integrating mass-spectroscopy data from Nakamori et al. 17. The amount of diborane produced follows nicely an exponential behavior as a function of formation enthalpy, as indicated by the fitted line $\alpha \exp \left[\beta \Delta H_{f}\right]$ with $\alpha=4.089$ and $\beta=0.05148$.

expect the full release reaction to have a minimum temperature as dictated by its thermodynamics.

\subsection{Relationship between Formation Enthalpy and Diborane Production}

In order to estimate the concentration of Sc needed to suitably suppress diborane production, we plot in Fig. 2 the amount of diborane produced (relative to hydrogen produced) versus formation enthalpy for $\mathrm{Al}\left(\mathrm{BH}_{4}\right)_{3}, \mathrm{Zn}\left(\mathrm{BH}_{4}\right)_{2}$, and $\mathrm{Mn}\left(\mathrm{BH}_{4}\right)_{2}$. The data for diborane production was obtained by integrating the mass-spectroscopy data from Nakamori et al. (units are arbitrary); for a given borohydride, we took the ratio of the integrated $\mathrm{B}_{2} \mathrm{H}_{6}$ data divided by the integrated $\mathrm{H}_{2}$ data, normalized so that $\mathrm{Al}\left(\mathrm{BH}_{4}\right)_{3}$ has a value of 1 [17. The formation enthalpy was calculated by us using DFT, with the formation enthalpy taken at the approximate temperature of the full desorption in the thermogravimetry curve, i.e. $340 \mathrm{~K}, 400 \mathrm{~K}$, and $470 \mathrm{~K}$ for $\mathrm{Al}\left(\mathrm{BH}_{4}\right)_{3}, \mathrm{Zn}\left(\mathrm{BH}_{4}\right)_{2}$, and $\mathrm{Mn}\left(\mathrm{BH}_{4}\right)_{2}$, respectively.

As mentioned above, the Pauling electronegativity is only a coarse predictor of a borohydride's tendency to produce diborane. From the data in Fig. 2 it is apparent that formation enthalpy - and thus borohydride stability - is a more accurate predictor. Whereas the Pauling electronegativity would predict $\mathrm{Al}\left(\mathrm{BH}_{4}\right)_{3}$ to produce more diborane than $\mathrm{Mn}\left(\mathrm{BH}_{4}\right)_{2}$, due to the higher electronegativity of $\mathrm{Al}$ compared to $\mathrm{Mn}$ (1.61 compared to 1.55) [32, the formation enthalpy correctly predicts what actually happens: the less stable $\mathrm{Mn}\left(\mathrm{BH}_{4}\right)_{2}$ produces significantly more diborane than $\mathrm{Al}\left(\mathrm{BH}_{4}\right)_{3}$.

The data in Fig. 2 can be nicely fitted to an exponential function as $\alpha \exp \left[\beta \Delta H_{f}\right]$ with $\alpha=4.089$ and $\beta=0.05148$, although $\alpha$ is really arbitrary as we have chosen to normalize the value for $\mathrm{Al}\left(\mathrm{BH}_{4}\right)_{3}$ to 1 . An exponential fit-suggested by the Arrhenius equation - can be justified by first assuming that the formation 
enthalpy of a borohydride is proportional to the reaction enthalpy for diborane formation (this is reasonable, as replacing $\mathrm{B}$ and $\mathrm{H}_{2}$ by $\mathrm{B}_{2} \mathrm{H}_{6}$ simply shifts all of the formation enthalpies by a constant), and then assuming that the reaction enthalpy for diborane formation is proportional to the activation enthalpy. It follows that, in order to reduce diborane production in $\mathrm{Al}\left(\mathrm{BH}_{4}\right)_{3}$ down to less than $5 \%$ of its current value, i.e. 1 to 0.05 , we need an enthalpy of formation of $-85.5 \mathrm{~kJ} / \mathrm{mol} \mathrm{BH}_{4}$.

Unfortunately, as there is experimental data only for 3 borohydrides which produce diborane in any significant amount, we cannot fully rely on this exponential fit. Furthermore, it is worth mentioning that - while we assume here the experimental data is for the pure borohydrides, and find this to be the most likely case - there have been known difficulties synthesizing certain borohydrides; for example, attempts to synthesize $\mathrm{Sc}\left(\mathrm{BH}_{4}\right)_{3}$ have been known to form $\operatorname{LiSc}\left(\mathrm{BH}_{4}\right)_{4}$ under certain synthesis conditions [54]. For this reason, we also look to other studies on borohydride alloys which have successfully suppressed diborane production in order to further verify our criteria for diborane production. In particular, we found two experimental studies involving $\mathrm{Mg}-\mathrm{Zn}$ borohydride alloys done by the same groups [34,55]. It was found that diborane production in a $\mathrm{Mg}_{1-x} \mathrm{Zn}_{x}\left(\mathrm{BH}_{4}\right)_{2}$ alloy was dependent on the concentration of $\mathrm{Zn}$; for values of $x$ greater than 0.248 (i.e. $24.8 \% \mathrm{Zn}$ ), at least small amounts of diborane were measured while for values of $x$ less than 0.167 no diborane was found. Comparing this to the known formation enthalpies for $\mathrm{Mg}_{1-x} \mathrm{Zn}_{x}\left(\mathrm{BH}_{4}\right)_{2}$ alloys (taken at $500 \mathrm{~K}$ ) 33, we find the cutoff for diborane formation in the $\mathrm{Mg}-\mathrm{Zn}$ alloy between -88 and $-79 \mathrm{~kJ} / \mathrm{mol} \mathrm{BH}_{4}$, in excellent agreement to our predicted value of $-85.5 \mathrm{~kJ} / \mathrm{mol} \mathrm{BH}_{4}$ for $\mathrm{Al}\left(\mathrm{BH}_{4}\right)_{3}$. Combining the exponential fit of thermodynamic data of known borohydrides with this data from $\mathrm{Mg}_{1-x} \mathrm{Zn}_{x}\left(\mathrm{BH}_{4}\right)_{2}$ alloys, we thus estimate the cutoff formation enthalpy for diborane production in general to be around $-80 \mathrm{~kJ} / \mathrm{mol} \mathrm{BH} 4$. This estimate for the formation enthalpy includes both the zero-point energy and temperature effects. Adjusting it to be suitable for energy-only calculations - which are significantly simpler than including zero-point motion and temperature effectsour data suggests a cutoff of $-110 \mathrm{~kJ} / \mathrm{mol} \mathrm{BH}_{4}$.

We note that this estimate for the formation enthalpy required to suppress diborane applies to either pure borohydrides or solid solutions of different borohydrides, as this is the data we have included in our model. However, our finding might even be more general, as the following example suggests. A study by $\mathrm{Gu}$ et al. found that diborane release is fully suppressed for $\mathrm{Zn}\left(\mathrm{BH}_{4}\right)_{2}$ when it is combined with ammonia to form $\mathrm{Zn}\left(\mathrm{BH}_{4}\right)_{2} \cdot 2 \mathrm{NH}_{3}$ [56]. A recent 2015 study on ammine metal borohydrides claims that ammonia, when combined with borohydrides which have a highly electronegative cation (as in the case with $\left.\mathrm{Zn}\left(\mathrm{BH}_{4}\right)_{2}\right)$, stabilizes the borohydride [57. Doing a simple energy calculation for the formation enthalpy of $\mathrm{Zn}\left(\mathrm{BH}_{4}\right)_{2} \cdot 2 \mathrm{NH}_{3}$ (i.e., not including zero-point energy or temperature effects), we find a value of $-165 \mathrm{~kJ} / \mathrm{mol} \mathrm{BH}_{4}$, well below the energy-only threshold mentioned above of $-110 \mathrm{~kJ} / \mathrm{mol} \mathrm{BH}_{4}$. For reference, the energy-only formation enthalpy of $\mathrm{Zn}\left(\mathrm{BH}_{4}\right)_{2}$ is only $-17 \mathrm{~kJ} / \mathrm{mol} \mathrm{BH}_{4}$, while for $\mathrm{Sc}\left(\mathrm{BH}_{4}\right)_{3}$, which we know does not produce diborane, it is $-113 \mathrm{~kJ} / \mathrm{mol} \mathrm{BH}_{4}$. 
From this we can see that $\mathrm{NH}_{3}$ significantly stabilizes $\mathrm{Zn}\left(\mathrm{BH}_{4}\right)_{2}$ and this stabilization is likely responsible for the suppression of diborane. Our criteria for diborane suppression seems to apply not only to borohydride alloys, but also to borohydrides modified through other means, such as additives. It is thus conceivable that our guidelines for diborane suppression are applicable to an even larger group of materials. If this is the case, our criteria could be used in conjunction with a variety of methods in order to design borohydrides which both have a low desorption temperature and no diborane production. Examples already exist where such a criteria could be useful, e.g. a recent study found that $\mathrm{Mg}\left(\mathrm{BH}_{4}\right)_{2}$ exhibits a significantly reduced hydrogen desorption temperature when combined with fluorographite [58, however, this hydrogen release is accompanied by diborane gas. Even more interesting, when $\mathrm{LiBH}_{4}$ is added, so that a $\mathrm{Mg}\left(\mathrm{BH}_{4}\right)_{2} / \mathrm{LiBH}_{4} /$ fluorographite composite is formed, a low hydrogen desorption temperature combined with no diborane gas formation is observed. It is very likely that adding the $\mathrm{LiBH}_{4}$ stabilized the structure, suppressing the diborane formation.

Applying our estimate for the cutoff formation enthalpy to the case of Sc doping in $\mathrm{Al}\left(\mathrm{BH}_{4}\right)_{3}$, we find that approximately $80 \% \mathrm{Sc}$ concentration is required to suppress diborane production. It is worth noting at this point that, due to the cost of $\mathrm{Sc}$, it is not a suitable hydrogen storage material in any large amount; certainly not as $80 \%$ of an alloy. But, we see the strength and novelty of our study in that we were able to find a precise predictor of diborane production in metal borohydrides and provide accurate guidelines for the tuning of already existing borohydrides and the design of new ones. Note that the formation enthalpy can also be tuned by other means, such as stress, which is already work in progress. We had chosen Sc due to it being one of the most stable borohydrides with the same valence as $\mathrm{Al}\left(\mathrm{BH}_{4}\right)_{3}$ making it an ideal alloyant for a case study. Furthermore, other studies on borohydride alloys have found that certain metal combinations do not seem to suppress diborane production (e.g. $\mathrm{Li}-\mathrm{Al}$ and $\mathrm{Li}-\mathrm{Mn}$ alloys), most likely due to the phase separation of the solid solution, causing the constituents to undergo their decomposition reactions separately [39, 53. For example, $\mathrm{Li}$ et al. found that an alloy formed with $\mathrm{LiBH}_{4}$ and $\mathrm{Zn}\left(\mathrm{BH}_{4}\right)_{2}$ or $\mathrm{Al}\left(\mathrm{BH}_{4}\right)_{3}$ disproportionate, possibly due to the incompatible structures between the borohydrides [26]. It is important that the individual borohydrides constituting the alloy have similar structures, as in the case of a $\mathrm{Al}-\mathrm{Sc}$ and $\mathrm{Mg}-\mathrm{Zn}$ borohydride alloy, so as to prevent phase separation.

\section{Conclusions}

$A b$ initio calculations were performed to study the hydrogen storage material $\mathrm{Al}\left(\mathrm{BH}_{4}\right)_{3}$ and the effect of Sc alloying. It was found that the thermodynamic properties of Sc-alloyed $\mathrm{Al}\left(\mathrm{BH}_{4}\right)_{3}$ are approximately the weighted average of the properties of pure $\mathrm{Al}\left(\mathrm{BH}_{4}\right)_{3}$ and $\mathrm{Sc}\left(\mathrm{BH}_{4}\right)_{3}$. It was furthermore found that proper accounting for van der Waals interactions is necessary to achieve an accu-

rate formation enthalpy due to the weak interactions among individual $\mathrm{Al}\left(\mathrm{BH}_{4}\right)_{3}$ 
molecules in the $\mathrm{Al}\left(\mathrm{BH}_{4}\right)_{3}$ solid. In attempting to estimate the ideal concentration of Sc needed to suppress diborane production, we have found the formation enthalpy of a borohydride to be a better predictor than the Pauling electronegativity, and estimate approximately 80 at\% Sc would be needed to suppress diborane production. However, work done on diborane suppression in borohydrides is relatively scarce and we encourage further work on Al-Sc borohydride alloys at multiple concentrations. We have shown that, alternatively to trying to destabilize candidate hydrogen storage materials such as $\mathrm{LiBH}_{4}$ with too high of a hydrogen release temperature via alloying, it is also possible to stabilize materials such as $\mathrm{Al}\left(\mathrm{BH}_{4}\right)_{3}$ with an already low hydrogen desorption temperature and thus suppress the unwanted diborane byproduct. Because of $\mathrm{Al}\left(\mathrm{BH}_{4}\right)_{3}$ 's especially low hydrogen release temperature compared to other borohydrides, modifying $\mathrm{Al}\left(\mathrm{BH}_{4}\right)_{3}$ primarily so as to not produce diborane, especially via alloying with more stable borohydrides, may be a promising avenue for developing a viable hydrogen storage material within the class of borohydrides.

\section{References}

\section{References}

[1] M. Kunowsky, J. P. Marco-Lózar, A. Linares-Solano, Material demands for storage technologies in a hydrogen economy, J. Renew. Energy 2013 (2013) 1-16. doi:10.1155/2013/878329.

[2] D. Durbin, C. Malardier-Jugroot, Review of hydrogen storage techniques for on board vehicle applications, Int. J. Hydrogen Energy 38 (34) (2013) 14595-14617. doi:10.1016/j.ijhydene.2013.07.058.

[3] G. W. Crabtree, M. S. Dresselhaus, M. V. Buchanan, The hydrogen economy, Phys. Today 57 (12) (2004) 39-44. doi:10.1063/1.1878333

[4] D. Harrison, E. Welchman, Y. J. Chabal, T. Thonhauser, Materials for hydrogen storage, in: J. Yan (Ed.), Vol. 5 Energy Storage, Handb. Clean Energy Syst., Wiley, Hoboken, NJ, 2015, pp. 2665-2683. doi:10.1002/ 9781118991978,

[5] R. Ahluwalia, T. Hua, J. Peng, On-board and off-board performance of hydrogen storage options for light-duty vehicles, Int. J. Hydrogen Energy 37 (3) (2012) 2891-2910. doi:10.1016/j.ijhydene.2011.05.040.

[6] J. Yang, A. Sudik, C. Wolverton, D. J. Siegel, High capacity hydrogen storage materials: attributes for automotive applications and techniques for materials discovery, Chem. Soc. Rev. 39 (2) (2010) 656-675. doi: $10.1039 / \mathrm{b} 802882 \mathrm{f}$.

[7] DOE targets for onboard hydrogen storage systems for light-duty vehicles, retrieved from http://energy.gov/sites/prod/files/2014/03/ f12/targets_onboard_hydro_storage.pdf, US Department of Energy, - 
for a good side-by-side comparison between the old and new DOE targets see Ref. 6] (2009).

[8] J. Graetz, New approaches to hydrogen storage, Chem. Soc. Rev. 38 (1) (2009) 73-82. doi:10.1039/b718842k.

[9] E. Rönnebro, Development of group II borohydrides as hydrogen storage materials, Curr. Opin. Solid State Mater. Sci. 15 (2) (2011) 44-51. doi: $10.1016 / \mathrm{j}$.cossms.2010.10.003.

[10] H.-W. Li, Y. Yan, S.-i. Orimo, A. Züttel, C. M. Jensen, Recent progress in metal borohydrides for hydrogen storage, Energies 4 (1) (2011) 185-214. doi:10.3390/en4010185.

[11] L. H. Rude, T. K. Nielsen, D. B. Ravnsbæk, U. Bösenberg, M. B. Ley, B. Richter, L. M. Arnbjerg, M. Dornheim, Y. Filinchuk, F. Besenbacher, T. R. Jensen, Tailoring properties of borohydrides for hydrogen storage: A review, Phys. Status Solidi A 208 (8) (2011) 1754-1773. doi:10.1002/ pssa.201001214.

[12] I. P. Jain, P. Jain, A. Jain, Novel hydrogen storage materials: A review of lightweight complex hydrides, J. Alloys Compd. 503 (2) (2010) 303-339. doi:10.1016/j.jallcom.2010.04.250.

[13] S.-i. Orimo, Y. Nakamori, J. R. Eliseo, A. Züttel, C. M. Jensen, Complex hydrides for hydrogen storage, Chem. Rev. 107 (10) (2007) 4111-4132. doi:10.1021/cr0501846.

[14] T. Umegaki, J.-M. Yan, X.-B. Zhang, H. Shioyama, N. Kuriyama, Q. Xu, Boron- and nitrogen-based chemical hydrogen storage materials, Int. J. Hydrogen Energy 34 (5) (2009) 2303-2311. doi:10.1016/j.ijhydene. 2009.01 .002

[15] L. George, S. K. Saxena, Structural stability of metal hydrides, alanates and borohydrides of alkali and alkali- earth elements: A review, Int. J. Hydrogen Energy 35 (11) (2010) 5454-5470. doi:10.1016/j.ijhydene. 2010.03 .078

[16] H.-W. Li, K. Kikuchi, Y. Nakamori, N. Ohba, K. Miwa, S. Towata, S. Orimo, Dehydriding and rehydriding processes of well-crystallized $\mathrm{Mg}\left(\mathrm{BH}_{4}\right)_{2}$ accompanying with formation of intermediate compounds, Acta Mater. 56 (6) (2008) 1342-1347. doi:10.1016/j.actamat.2007.11.023.

[17] Y. Nakamori, H.-W. Li, K. Kikuchi, M. Aoki, K. Miwa, S. Towata, S. Orimo, Thermodynamical stabilities of metal-borohydrides, J. Alloys Compd. 446-447 (2007) 296-300. doi:10.1016/j.jallcom.2007.03.144.

[18] A. F. Dalebrook, W. Gan, M. Grasemann, S. Moret, G. Laurenczy, Hydrogen storage: beyond conventional methods., Chem. Commun. 49 (78) (2013) 8735-8751. doi:10.1039/c3cc43836h. 
[19] Z. Łodziana, Multivalent metal tetrahydroborides of Al, Sc, Y, Ti, and Zr, Phys. Rev. B 81 (14) (2010) 144108. doi:10.1103/PhysRevB.81.144108.

[20] J. G. Goodwin, Jr., H. C. Mercado, S. Greenway, X. Mo, K. Hongsirikarn, J. Zhang, V.B.4 fundamental effects of impurities on fuel cell performance and durability, retrieved from http://www.hydrogen.energy.gov/pdfs/ progress11/v_b_4_goodwin_2011.pdf, US Department of Energy (2011).

[21] K. Miwa, N. Ohba, S.-i. Towata, Y. Nakamori, A. Züttel, S.-i. Orimo, First-principles study on thermodynamical stability of metal borohydrides: Aluminum borohydride $\mathrm{Al}\left(\mathrm{BH}_{4}\right)_{3}$, J. Alloys Compd. 446-447 (2007) 310314. doi:10.1016/j.jallcom.2006.11.140

[22] J. J. Vajo, S. L. Skeith, F. Mertens, Reversible storage of hydrogen in destabilized $\mathrm{LiBH}_{4}$, J. Phys. Chem. B 109 (9) (2005) 3719-3722. doi: 10.1021/jp040769o

[23] S. V. Alapati, K. J. Johnson, D. S. Sholl, Using first principles calculations to identify new destabilized metal hydride reactions for reversible hydrogen storage, Phys. Chem. Chem. Phys. 9 (12) (2007) 1438-1452. doi:10.1039/ b617927d.

[24] S. V. Alapati, J. K. Johnson, D. S. Sholl, Large-scale screening of metal hydride mixtures for high-capacity hydrogen storage from first-principles calculations, J. Phys. Chem. C 112 (14) (2008) 5258-5262. doi:10.1021/ jp800630s.

[25] E. A. Nickels, M. O. Jones, W. I. F. David, S. R. Johnson, R. L. Lowton, M. Sommariva, P. P. Edwards, Tuning the decomposition temperature in complex hydrides: synthesis of a mixed alkali metal borohydride, Angew. Chemie Int. Ed. 47 (15) (2008) 2817-2819. doi:10.1002/anie. 200704949

[26] H.-W. Li, S. Orimo, Y. Nakamori, K. Miwa, N. Ohba, S. Towata, A. Züttel, Materials designing of metal borohydrides: Viewpoints from thermodynamical stabilities, J. Alloys Compd. 446-447 (2007) 315-318. doi: $10.1016 / \mathrm{j} \cdot \mathrm{jallcom} .2007 .02 .156$

[27] S. H. Lee, V. R. Manga, Z.-K. Liu, Effect of Mg, Ca, and Zn on stability of $\mathrm{LiBH}_{4}$ through computational thermodynamics, Int. J. Hydrogen Energy 35 (13) (2010) 6812-6821. doi:10.1016/j.ijhydene.2010.04.014

[28] M. J. van Setten, G. A. de Wijs, G. Brocks, Ab initio study of the effects of transition metal doping of $\mathrm{Mg}_{2} \mathrm{NiH}_{4}$, Phys. Rev. B 76 (7) (2007) 075125. doi:10.1103/PhysRevB.76.075125

[29] H. W. Brinks, A. Fossdal, B. C. Hauback, Adjustment of the stability of complex hydrides by anion substitution, J. Phys. Chem. C 112 (14) (2008) 5658-5661. doi:10.1021/jp7100754. 
[30] H.-W. Li, K. Kikuchi, Y. Nakamori, K. Miwa, S. Towata, S. Orimo, Effects of ball milling and additives on dehydriding behaviors of wellcrystallized $\mathrm{Mg}\left(\mathrm{BH}_{4}\right)_{2}$, Scr. Mater. 57 (8) (2007) 679-682. doi:10.1016/ j.scriptamat.2007.06.052

[31] Y. Nakamori, K. Miwa, A. Ninomiya, H. Li, N. Ohba, S.-i. Towata, A. Züttel, S.-i. Orimo, Correlation between thermodynamical stabilities of metal borohydrides and cation electronegativites: First-principles calculations and experiments, Phys. Rev. B 74 (4) (2006) 045126. doi: 10.1103/PhysRevB.74.045126.

[32] A. L. Allred, Electronegativity values from thermochemical data, J. Inorg. Nucl. Chem. 17 (3-4) (1961) 215-221. doi:10.1016/0022-1902(61) 80142-5

[33] D. Harrison, T. Thonhauser, Tuning the hydrogen desorption of $\mathrm{Mg}\left(\mathrm{BH}_{4}\right)_{2}$ through Zn alloying, Phys. Rev. B 90 (12) (2014) 125152. doi:10.1103/ PhysRevB.90.125152.

[34] E. Albanese, G. N. Kalantzopoulos, J. G. Vitillo, E. Pinatel, B. Civalleri, S. Deledda, S. Bordiga, B. C. Hauback, M. Baricco, Theoretical and experimental study on $\mathrm{Mg}\left(\mathrm{BH}_{4}\right)_{2}-\mathrm{Zn}\left(\mathrm{BH}_{4}\right)_{2}$ mixed borohydrides, J. Alloys Compd. 580 (2013) S282-S286. doi:10.1016/j.jallcom.2013.02.165.

[35] R. Černý, G. Severa, D. B. Ravnsbæk, Y. Filinchuk, V. D’Anna, H. Hagemann, D. Haase, C. M. Jensen, T. R. Jensen, $\mathrm{NaSc}\left(\mathrm{BH}_{4}\right)_{4}$ : A novel scandium-based borohydride, J. Phys. Chem. C 114 (2) (2010) 1357-1364. doi:10.1021/jp908397w.

[36] R. Černý, D. B. Ravnsbæk, G. Severa, Y. Filinchuk, V. D’Anna, H. Hagemann, J. Skibsted, C. M. Jensen, T. R. Jensen, Structure and characterization of $\mathrm{KSc}\left(\mathrm{BH}_{4}\right)_{4}$, J. Phys. Chem. C 114 (2010) 19540-19549. doi:10.1021/jp106280v.

[37] I. Dovgaliuk, V. Ban, Y. Sadikin, R. Černý, L. Aranda, N. Casati, M. Devillers, Y. Filinchuk, The first halide-free bimetallic aluminum borohydride: Synthesis, structure, stability, and decomposition pathway, J. Phys. Chem. C 118 (1) (2014) 145-153. doi:10.1021/jp409217x.

[38] C. Kim, S.-J. Hwang, R. C. Bowman, Jr., J. W. Reiter, J. A. Zan, J. G. Kulleck, H. Kabbour, E. H. Majzoub, V. Ozolins, $\operatorname{LiSc}\left(\mathrm{BH}_{4}\right)_{4}$ as a hydrogen storage material: Multinuclear high-resolution solid-state NMR and firstprinciples density functional theory studies, J. Phys. Chem. C 113 (22) (2009) 9956-9968. doi:10.1021/jp9011685.

[39] I. Lindemann, A. Borgschulte, E. Callini, A. Züttel, L. Schultz, O. Gutfleisch, Insight into the decomposition pathway of the complex hydride $\mathrm{Al}_{3} \mathrm{Li}_{4}\left(\mathrm{BH}_{4}\right)_{13}$, Int. J. Hydrogen Energy 38 (6) (2013) 2790-2795. doi: $10.1016 / j$.ijhydene.2012.12.012 
[40] J. Yang, A. Sudik, C. Wolverton, Destabilizing $\mathrm{LiBH}_{4}$ with a metal $(\mathrm{M}=$ $\mathrm{Mg}, \mathrm{Al}, \mathrm{Ti}, \mathrm{V}, \mathrm{Cr}$, or $\mathrm{Sc}$ ) or metal hydride $\left(\mathrm{MH}_{2}=\mathrm{MgH}_{2}, \mathrm{TiH}_{2}\right.$, or $\left.\mathrm{CaH}_{2}\right)$, J. Phys. Chem. C 111 (51) (2007) 19134-19140. doi:10.1021/jp076434z.

[41] G. Kresse, J. Furthmüller, Efficient iterative schemes for ab initio totalenergy calculations using a plane-wave basis set, Phys. Rev. B 54 (16) (1996) 11169-11186. doi:10.1103/PhysRevB.54.11169.

[42] G. Kresse, D. Joubert, From ultrasoft pseudopotentials to the projector augmented-wave method, Phys. Rev. B 59 (3) (1999) 1758-1775. doi: 10.1103/PhysRevB.59.1758

[43] S. Aldridge, A. J. Blake, A. J. Downs, R. O. Gould, S. Parsons, C. R. Pulham, Some tetrahydroborate derivatives of aluminium: crystal structures of dimethylaluminium tetrahydroborate and the $\alpha$ and $\beta$ phases of aluminium tris(tetrahydroborate) at low temperature, J. Chem. Soc., Dalton Trans. (6) (1997) 1007-1012. doi:10.1039/a607843e.

[44] P. Choudhury, V. R. Bhethanabotla, E. K. Stefanakos, Manganese borohydride as a hydrogen-storage candidate: First-principles crystal structure and thermodynamic properties, J. Phys. Chem. C 113 (30) (2009) 1341613424. doi:10.1021/jp9015933.

[45] M. J. van Setten, M. A. Uijttewaal, G. A. de Wijs, R. A. de Groot, Thermodynamic stability of boron: the role of defects and zero point motion., J. Am. Chem. Soc. 129 (9) (2007) 2458-2465. doi:10.1021/ja0631246

[46] T. Thonhauser, S. Zuluaga, C. A. Arter, K. Berland, E. Schröder, P. Hyldgaard, Spin signature of nonlocal correlation binding in metalorganic frameworks, Phys. Rev. Lett. 115 (13) (2015) 136402. doi: 10.1103/PhysRevLett.115.136402

[47] K. Berland, V. R. Cooper, K. Lee, E. Schröder, T. Thonhauser, P. Hyldgaard, B. I. Lundqvist, van der Waals forces in density functional theory: a review of the vdW-DF method, Reports Prog. Phys. 78 (6) (2015) 066501. doi:10.1088/0034-4885/78/6/066501.

[48] T. Thonhauser, V. R. Cooper, S. Li, A. Puzder, P. Hyldgaard, D. C. Langreth, Van der Waals density functional: Self-consistent potential and the nature of the van der Waals bond, Phys. Rev. B 76 (12) (2007) 125112. doi:10.1103/PhysRevB.76.125112

[49] D. C. Langreth, B. I. Lundqvist, S. D. Chakarova-Käck, V. R. Cooper, M. Dion, P. Hyldgaard, A. Kelkkanen, J. Kleis, L. Kong, S. Li, P. G. Moses, E. D. Murray, A. Puzder, H. Rydberg, E. Schröder, T. Thonhauser, A density functional for sparse matter, J. Phys. Condens. Matter 21 (8) (2009) 084203. doi:10.1088/0953-8984/21/8/084203. 
[50] A. Togo, F. Oba, I. Tanaka, First-principles calculations of the ferroelastic transition between rutile-type and $\mathrm{CaCl}_{2}$-type $\mathrm{SiO}_{2}$ at high pressures, Phys. Rev. B 78 (2008) 134106.

[51] M. J. van Setten, G. A. de Wijs, M. Fichtner, G. Brocks, A density functional study of $\alpha-\mathrm{Mg}\left(\mathrm{BH}_{4}\right)_{2}$, Chem. Mater. 20 (15) (2008) $4952-4956$. doi:10.1021/cm800358k.

[52] H. Hemmes, A. Driessen, R. Griessen, Thermodynamic properties of hydrogen at pressures up to $1 \mathrm{Mbar}$ and temperatures between 100 and $1000 \mathrm{~K}, \mathrm{~J}$. Phys. C 19 (19) (1986) 3571-3585. doi:10.1088/0022-3719/19/19/013.

[53] M. Paskevicius, M. B. Ley, D. A. Sheppard, T. R. Jensen, C. E. Buckley, Eutectic melting in metal borohydrides., Phys. Chem. Chem. Phys. 15 (45) (2013) 19774-19789. doi:10.1039/c3cp53920b.

[54] H. Hagemann, M. Longhini, J. W. Kaminski, T. A. Wesolowski, R. Černý, N. Penin, M. H. Sørby, B. C. Hauback, G. Severa, C. M. Jensen, LiSc $\left(\mathrm{BH}_{4}\right)_{4}$ : A novel salt of $\mathrm{Li}^{+}$and discrete $\mathrm{Sc}\left(\mathrm{BH}_{4}\right)_{4}^{-}$complex anions, J. Phys. Chem. A 112 (33) (2008) 7551-7555. doi:10.1021/jp803201q.

[55] G. N. Kalantzopoulos, J. G. Vitillo, E. Albanese, E. Pinatel, B. Civalleri, S. Deledda, S. Bordiga, M. Baricco, B. C. Hauback, Hydrogen storage of $\mathrm{Mg}-\mathrm{Zn}$ mixed metal borohydrides, J. Alloys Compd. 615 (2014) S702âS705. doi:10.1016/j.jallcom.2013.12.258.

[56] Q. Gu, L. Gao, Y. Guo, Y. Tan, Z. Tang, K. S. Wallwork, F. Zhang, $\mathrm{X}$. Yu, Structure and decomposition of zinc borohydride ammonia adduct: towards a pure hydrogen release, Energy Environ. Sci. 5 (2012) 7590-7600. doi:10.1039/C2EE02485C.

[57] L. H. Jepsen, M. B. Ley, Y. Filinchuk, F. Besenbacher, T. R. Jensen, Tailoring the properties of ammine metal borohydrides for solid-state hydrogen storage, ChemSusChem 8 (8) (2015) 1452-1463. doi:10.1002/cssc. 201500029.

[58] L. Zhang, J. Zheng, L. Chen, X. Xiao, T. Qin, Y. Jiang, S. Li, H. Ge, Q. Wang, Remarkable enhancement in dehydrogenation properties of $\mathrm{Mg}\left(\mathrm{BH}_{4}\right)_{2}$ modified by the synergetic effect of fluorographite and $\mathrm{LiBH}_{4}$, Int. J. Hydrogen Energy 40 (41) (2015) 14163-14172. doi:10.1016/j. ijhydene.2015.08.090. 